\title{
Study on hydrogen emission performance of FCEV
}

\author{
Xinjian Yuan ${ }^{1}$ \\ ${ }^{1}$ School of Automotive Engineering,Natong Institute OF Technology,Nantong Jiangsu,China
}

\begin{abstract}
Hydrogen leakage and emission will bring adverse effects to the environment and human health. When it enters a certain concentration range, it will bring the potential explosion. Hydrogen emissions from fuel cell vehicles can be divided into two sources: normal operation of the system and leakage under abnormal circumstances. This paper mainly uses the flowmeter method to measure the hydrogen emission from fuel cell electric vehicle (FCEV). The different emission characteristics of different types of FCEV under idle and steady cycle conditions were analyzed. The hydrogen emission levels of different types of FCEV under idle and cycle conditions were verified by analyzing and processing the experimental data through a certain amount of hydrogen emission tests of FCEV.
\end{abstract}

\section{Hazard and source of hydrogen emission from FCEV}

Since hydrogen enters $4 \%-75 \%$ in air and reaches $4 \%$ $94 \%$ in oxygen, it has reached its explosion range ${ }^{[1]}$. In the case of air circulation, it is easier to gather the concentration in the local area to reach the above two kinds of range, resulting in the potential explosion. From the environmental point of view, if it is emitted too much, it is easy to cause a lot of harmful problems to the environment, and it is easy to cause damage to the atmosphere.

Hydrogen emissions from FCEV can be divided into normal operation of the system and leakage under abnormal conditions.

(1) Normal hydrogen emissions

Normal hydrogen discharge includes residual hydrogen in the reactor that has not fully reacted and excess hydrogen discharged to remove excess water from the reactor. In general, the concentration of hydrogen discharged from the outlet of the air loop is low, and a large amount of hydrogen will be discharged from the scavenge outlet of the hydrogen loop. The normal hydrogen emission depends on the operating principle, system composition, manufacturing process level, design level, control strategy of the control software and other combined factors of the fuel cell system ${ }^{[2]}$. Since hydrogen is not a harmful gas, the total amount of gas emitted is not the focus. The main concern is safety, which is that the concentration does not reach the minimum combustion limit for hydrogen. The emission location of normal hydrogen emission is clear, and the emission time is predictable and controllable.

(2) Abnormal hydrogen emissions

As with other gas-fueled vehicles, leaks are possible as long as there are connecting parts and pressure differences. The leakage under abnormal conditions is mainly manifested in the surface penetration of highpressure gas cylinders and pipelines. Failure of fasteners and seals; Looseness of various valves and defects such as microholes and cracks in the system ${ }^{[3]}$. Abnormal leakage is usually continuous, after a long time of shutdown, can reach a high concentration, thus forming a hidden danger. The cause and start time of the abnormal leak are incidental and difficult to detect.

\section{Experimental method and calculation}

\subsection{Test method}

The flowmeter method is to obtain hydrogen consumption by continuously measuring the flow rate of tail gas and integrating the measurement results at different times ${ }^{[4]}$. Schematic diagram of flowmeter method used in fuel cell vehicle is shown in Fig.1. The measurement accuracy of the flowmeter method mainly depends on the measurement accuracy of the flowmeter. 


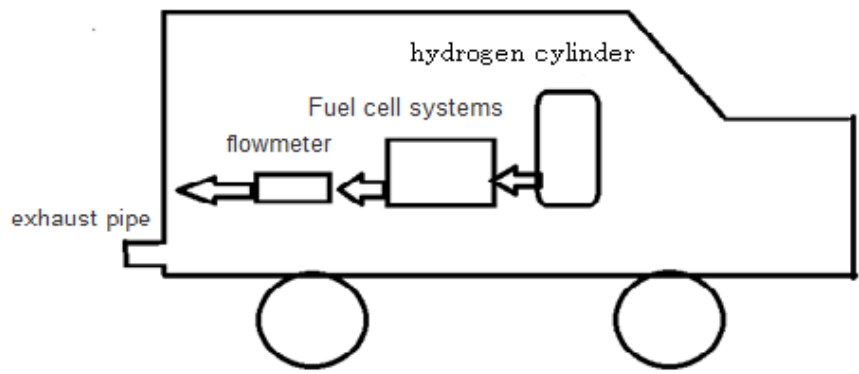

Fig. 1. Schematic diagram of flow meter method used to measure hydrogen emission from FCEV

(1) Advantages:

The flow meter used to measure hydrogen mass consumption can be directly arranged in the hydrogen flow pipeline, and will not affect the flow process of gas in the pipeline. Therefore, the flow meter method is the easiest one to be applied to the actual vehicle among the three hydrogen consumption detection methods.

The flow meter should be installed on the hydrogen supply pipe between the hydrogen bottle and the vehicle, which is the most convenient hydrogen consumption detection method in the hub test rig and on the road test. For most liquid or gas flow measuring instruments, the flow rate is inferred by measuring the flow velocity or kinetic energy change of the fluid. The flow rate is determined by the pressure difference that pushes the fluid through a length of pipe. Since the cross-sectional area of the pipe is known and kept constant, the average flow rate indicates the flow rate.

(2) Disadvantages:

The measurement accuracy of the flowmeter in the transient and small flow conditions will restrict the overall measurement accuracy, and the accuracy in the transient low flow rate is low.

\subsection{Test calculation method}

The formulas for calculating actual hydrogen consumption, theoretical hydrogen consumption and hydrogen emission of each vehicle are respectively Formula 1, Formula 2, Formula 3 and Formula $4^{[5]}$.

$$
m_{\mathrm{H}_{2}}=\int_{T_{1}}^{T_{2}} q_{\mathrm{H}_{2}} \cdot \mathrm{d} t
$$

Type: $\quad m_{\mathrm{H}_{2}} \quad--$ The measured hydrogen consumption of fuel cell stack, in gram $(\mathrm{g})$;

$$
q_{\mathrm{H}_{2}} \text { - The measured hydrogen flow rate of }
$$
the fuel cell stack is in grams per second $(\mathrm{g} / \mathrm{s})$.

$$
m_{H_{2}-\text { theo }}=\int_{T_{1}}^{T_{2}} q_{H_{2}-\text { heo }} \cdot d t
$$

Type: $m_{H_{2}-\text { theo }}$-The theoretical hydrogen consumption of fuel cell stack is in gram $(\mathrm{g})$;

$q_{\mathrm{H}_{2}-h e o}$ cell stacks, grams per second $(\mathrm{g} / \mathrm{s})$

The theoretical hydrogen flow rate is calculated according to Faraday formula:

$$
q_{\mathrm{H}_{2}-\text { theo }}=(M \times I \times N) /(n \times F)
$$

Type: $q_{\mathrm{H}_{2}-\text { theo }}$ - The theoretical hydrogen flow rate of fuel cell stack, in grams per second $(\mathrm{g} / \mathrm{s})$;

$\mathrm{M}-$ Molar mass of hydrogen, $2.016 \mathrm{~g} / \mathrm{mol}$;

I-Fuel cell stack current, unit is A (A);

$\mathrm{N}-$ Fuel cell stack number of cells per cell

$\mathrm{n}$-The number of electrons released per hydrogen molecule, 21;

F-Faraday constant, $96485 \mathrm{C} / \mathrm{mol}$.

$$
m_{\mathrm{H}_{2}-\text { emis }}=m_{\mathrm{H}_{2}}-m_{\mathrm{H}_{2} \text {-theo }}
$$

Type: $\quad m_{\mathrm{H}_{2}-\text { emis }}$-Mass of hydrogen gas emitted in grams $(\mathrm{g})$;

$m_{\mathrm{H}_{2}}$

-The measured hydrogen consumption of fuel cell stack is in gram $(\mathrm{g})$.

$m_{\mathrm{H}_{2}-\text { theo }}$ - The theoretical mass of hydrogen consumed is in grams $(\mathrm{g})$.

\subsection{Test design}

The test schematic diagram is shown in Fig.2.A pressure reducing valve is installed at the hydrogen intake port of the fuel cell anode to control the intake pressure, and the other end is connected with the hydrogen tank. A normally closed solenoid valve is installed at the exhaust port of the anode, and the discharge process is controlled by a controller. A flow meter is installed at the cathode inlet to measure the excess coefficient of the cathode air intake, and a pressure reducing valve is connected with the oxygen tank to control the intake pressure. To better simulate its working process, the fuel cells are also connected to the positive and negative poles of the load, equipped with a thermometer of the system temperature. The hydrogen emission performance of fuel cells under different conditions was simulated by orthogonal experiment under idle speed and cycle condition.

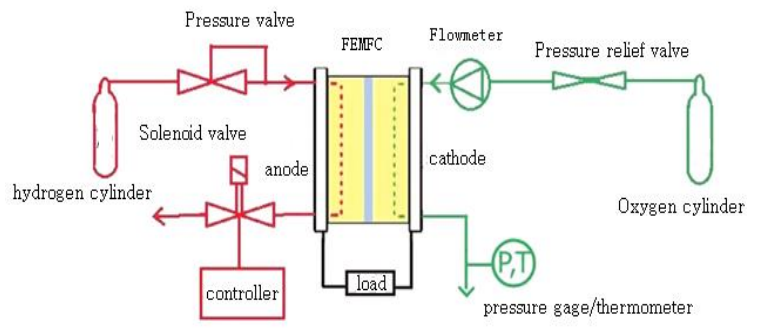

Fig.2. Schematic diagram of the test 


\section{Test vehicle information}

The experiment selects passenger small car (A) and commercial large city bus (B) to carry on the research. These two types of vehicles are widely used in the market, which can effectively compare the hydrogen emission levels of different vehicles, and summarize the

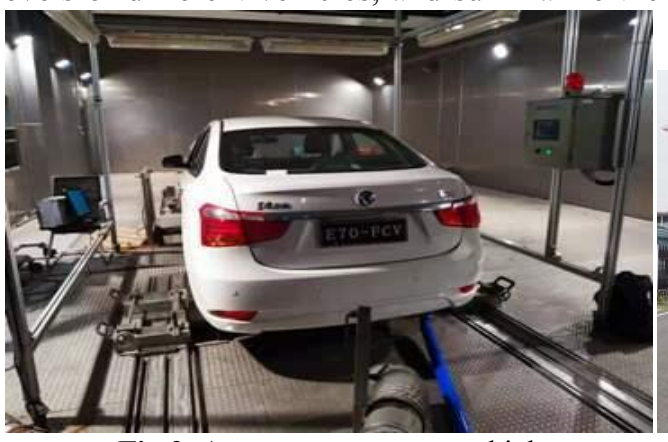

Fig.3. A passenger car test vehicle hydrogen emission characteristics of these two types of vehicles, laying a foundation for future research on reducing the hydrogen emission of FCEV. The following are the test working drawings and main technical parameters of the two test models.

Passenger car A and City bus B are shown in Fig.3 and 4.

The main technical parameters are shown in Table

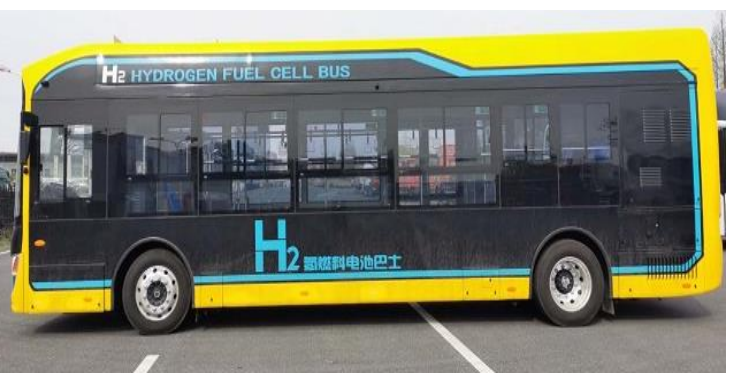

Fig. 4. City Bus B Test Vehicle 1and 2

Table 1.Main technical parameters of passenger car A

\begin{tabular}{|c|c|}
\hline Parameter item & Technical parameter \\
\hline Vehicle model & FCEV-1.1 \\
\hline VIN & LDP31B966KG712434 \\
\hline Body structure & Load-Supporting \\
\hline Curb weight $(\mathrm{Kg})$ & 1823 \\
\hline Length/width/height $(\mathrm{mm})$ & $4680 / 1720 / 1530$ \\
\hline Wheelbase $(\mathrm{mm})$ & 2700 \\
\hline Driving mode & $\mathrm{FF}$ \\
\hline
\end{tabular}

Table 2 Main technical parameters of hydrogen fuel city bus B

\begin{tabular}{|c|c|}
\hline Parameter item & Technical parameter \\
\hline Length/width/height $(\mathrm{mm})$ & $10490 / 2500 / 3450$ \\
\hline Wheelbase $(\mathrm{mm})$ & 6000 \\
\hline Number of tires & 6 \\
\hline rear tread $(\mathrm{mm})$ & 1880 \\
\hline Curb weight $(\mathrm{kg})$ & 11000 \\
\hline front/rear overhang $(\mathrm{mm})$ & $6200 / 2290$ \\
\hline Axle Load $(\mathrm{kg})$ & Hydrogen fuel cell \\
\hline Types of fuel cells & 2 \\
\hline Number of axes & $275 / 70 \mathrm{R} 22.5-18 \mathrm{PR}$ \\
\hline Tire size & $2120 / 2095$ \\
\hline front tread $(\mathrm{mm})$ & 17000 \\
\hline Total mass $(\mathrm{kg})$ & $70 / 14-27$ \\
\hline Rated passenger capacity (including driver) (number of seats) & 69 \\
\hline Maximum speed $(\mathrm{km} / \mathrm{h})$ & r \\
\hline
\end{tabular}

\section{Test data analysis}

Under idle and circulation conditions by orthogonal experiment method to simulate different environmental hydrogen emission performance of fuel cell, select four representative work $-10{ }^{\circ} \mathrm{C}$, the temperature $0{ }^{\circ} \mathrm{C}, 25{ }^{\circ} \mathrm{C}$ and $45{ }^{\circ} \mathrm{C}$, measuring each models under idle and circulation conditions theoretical hydrogen flow rate, hydrogen flow rate and testing record data and based on the calculation formula of 3 with type 1, type 2 and type 4 different models under different working temperature of hydrogen gas emissions.

(1) The measured data of Passenger Car A under idling speed and cycling conditions are shown in Table 3 and Table 4:

Table 3 Test data of each working temperature under idle condition

\begin{tabular}{|c|c|c|c|}
\hline $\begin{array}{c}\text { temperatu } \\
\text { re } /{ }^{\circ} \mathrm{C}\end{array}$ & Measured hydrogen flow $q_{H 2}(\mathrm{~g} / \mathrm{s})$ & $\begin{array}{c}\text { Time } \\
\mathrm{dt}(\mathrm{s})\end{array}$ & Theoretical hydrogen flow rate $q_{H 2-\text { theo }}(\mathrm{g} / \mathrm{s})$ \\
\hline-10 & 1.1 & 2 & 0.7 \\
\hline 0 & 0.95 & 2 & 0.65 \\
\hline 25 & 0.75 & 2 & 0.6 \\
\hline
\end{tabular}




\begin{tabular}{|c|c|c|c|}
\hline 45 & 0.65 & 2 & 0.5 \\
\hline $\begin{array}{l}\text { temperatu } \\
\text { re } /{ }^{\circ} \mathrm{C}\end{array}$ & Measured hydrogen flow $q_{H 2(\mathrm{~g} / \mathrm{s})}$ & $\begin{array}{l}\text { Time } \\
\mathrm{dt}(\mathrm{s})\end{array}$ & Theoretical hydrogen flow rate $q_{H 2-t h e o}(\mathrm{~g} / \mathrm{s})$ \\
\hline-10 & 1.28 & 5 & 0.61 \\
\hline 0 & 1.24 & 5 & 0.65 \\
\hline 25 & 1.18 & 5 & 0.67 \\
\hline 45 & 1.11 & 5 & 0.66 \\
\hline
\end{tabular}

(2) The measured data of city bus B under idle speed and cycle condition are shown in Table 5 and Table 6 :

Table 5 Test data of each working temperature under idle speed condition

\begin{tabular}{|c|c|c|c|}
\hline $\begin{array}{c}\text { temperatu } \\
\text { re/ }{ }^{\circ} \mathrm{C}\end{array}$ & Measured hydrogen flow $q_{H 2}(\mathrm{~g} / \mathrm{s})$ & $\begin{array}{c}\text { Time } \\
\mathrm{dt}(\mathrm{s})\end{array}$ & Theoretical hydrogen flow rate $q_{H 2 \text {-theo }}(\mathrm{g} / \mathrm{s})$ \\
\hline-10 & 1.8 & 2 & 1.25 \\
\hline 0 & 1.65 & 2 & 1.3 \\
\hline 25 & 1.45 & 2 & 1.2 \\
\hline 45 & 1.15 & 2 & 0.85 \\
\hline
\end{tabular}

Table 6 Test data of each working temperature under circulating condition

\begin{tabular}{|c|c|c|c|}
\hline $\begin{array}{c}\text { temperatu } \\
\text { re/ }{ }^{\circ} \mathrm{C}\end{array}$ & Measured hydrogen flow $q_{H 2}(\mathrm{~g} / \mathrm{s})$ & $\begin{array}{c}\text { Time } \\
\mathrm{dt}(\mathrm{s})\end{array}$ & Theoretical hydrogen flow rate $q_{H 2 \text {-theo }}(\mathrm{g} / \mathrm{s})$ \\
\hline-10 & 1.89 & 5 & 0.88 \\
\hline 0 & 1.70 & 5 & 0.86 \\
\hline 25 & 1.49 & 5 & 0.82 \\
\hline 45 & 1.41 & 5 & 0.84 \\
\hline
\end{tabular}

(3)Under the working temperature of $25^{\circ} \mathrm{C}$ in the in the urban cycle condition and the suburban cycle cycle condition, passenger car A and city bus B were condition, as shown in Table 7: respectively calculated to obtain the hydrogen emissions

Table 7 Hydrogen emissions under urban and suburban cycle conditions

\begin{tabular}{|c|c|c|c|}
\hline Car type & temperature $/{ }^{\circ} \mathrm{C}$ & \multicolumn{2}{|c|}{ Hydrogen Emissions $/ \mathrm{g}$} \\
\cline { 3 - 4 } & & urban drive cycle & suburban drive cycle \\
\hline A Passenger car & 25 & 1.6 & 0.66 \\
\hline B City Bus & 25 & 2.4 & 0.95 \\
\hline
\end{tabular}

(4) The hydrogen emission levels of passenger car A Equations 1, 2, 3 and 4 to calculate the hydrogen and city bus B were comprehensively compared, and the emissions under different vehicle types and temperatures. data in Tables 3, 4, 5 and 6 were substituted into The specific calculation results are shown in Table 8:

Table 8 Hydrogen emissions at different vehicle types and operating temperatures

\begin{tabular}{|c|c|c|c|}
\hline \multirow{2}{*}{ Car type } & \multirow{2}{*}{ temperature $/{ }^{\circ} \mathrm{C}$} & \multicolumn{2}{|c|}{ Hydrogen Emissions $/ \mathrm{g}$} \\
\cline { 2 - 4 } & & Idle condition & Cycle condition \\
\hline \multirow{3}{*}{ A Passenger car } & -10 & 0.8 & 3.35 \\
\cline { 2 - 4 } & 0 & 0.6 & 3.01 \\
\cline { 2 - 4 } & 25 & 0.3 & 2.26 \\
\cline { 2 - 4 } & 45 & 0.3 & 2.31 \\
\cline { 2 - 4 } & -10 & 1.1 & 5.04 \\
\cline { 2 - 4 } & 0 & 0.7 & 4.22 \\
\cline { 2 - 4 } & 25 & 0.5 & 3.35 \\
\hline \multirow{3}{*}{ B City Bus } & 45 & 0.6 & 3.31 \\
\hline
\end{tabular}

(5) Draw hydrogen emission curves under two drawn, as shown in Fig. 5; The hydrogen emission curves different working conditions.

According to Table 8, hydrogen emission curves of of the following two test models under cyclic working conditions are drawn, as shown in Fig. 6:: the following two test models under idle condition are 


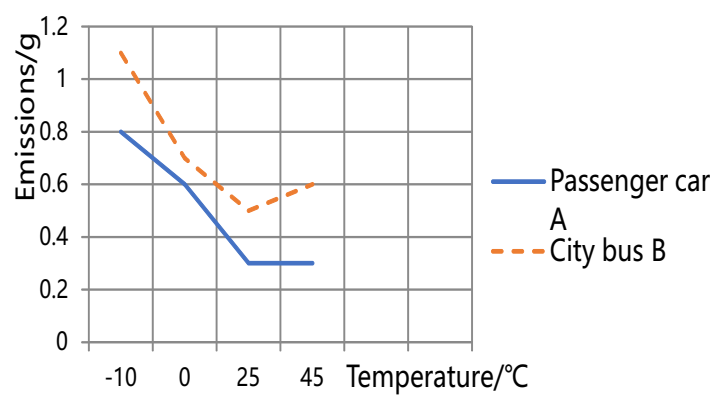

Fig. 5 .Hydrogen emission curve under idle speed

\section{5 summary}

According to the analysis of Fig.9 and Fig.10, the hydrogen emissions of the two test models decrease with the increase of working temperature under idle speed and cycle condition, and the hydrogen emissions of the two test models under cycle condition are higher than that under idle condition on the whole. Due to the difference in the quality of the preparation and the size of the fuel cell stack of the two test vehicles, the hydrogen emission of hydrogen passenger car $\mathrm{A}$ is lower than that of hydrogen city bus B.

Combined with table 7 , it can be seen that the hydrogen emissions of the two test vehicles under urban cycle condition are higher than those under suburban cycle condition. The specific reason is that FCEV need to start and stop frequently in the process of urban operation, and the overall running speed is low, which is not in the best running state. And in the urban cycle, the need to accelerate driving, resulting in an increase in hydrogen emissions. On the contrary, in the suburban cycle condition, the FCEV runs smoothly, the overall running speed is high, and the engine is in the best running state. Therefore, the hydrogen emission of FCEV in the suburban cycle condition is low.

According to the test results, the hydrogen emission of fuel cell vehicles also has an obvious corresponding relationship with the operating temperature. In the research process, engine control strategy, basic electrical performance, power generation demand, flow channel drainage demand, power size, water drainage demand and other characteristics also have a certain impact on the hydrogen emissions of FCEV.

\section{Acknowledgments :}

Young and middle-aged scientific research backbone training project OF Nantong Institute of Technology(ZQNGG407)

\section{References}

1. Zhang G,Yang Y.H., ,Liu F.(2018)Current Situation and Analysis of China's Hydrogen Fuel Cell Vehicle Standard System[J].Journal of Chongqing University of Technology( Natural Science), $12: 21-30$.

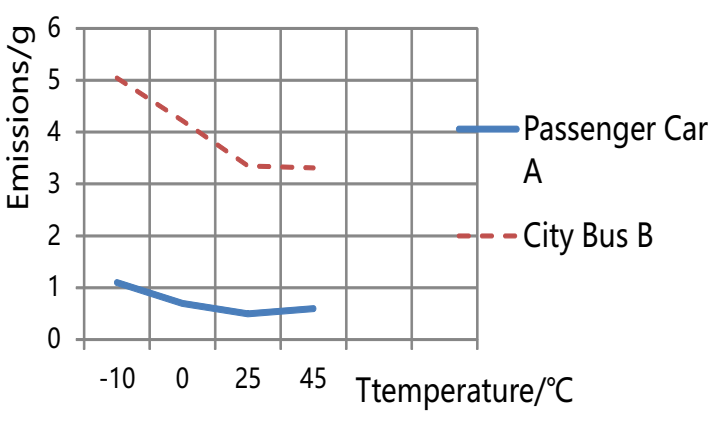

Fig.6. Hydrogen emission curve under cyclic conditions

2. Song Y.(2020) Modeling on Output Characteristic and Application of Proton Exchange Membrane Fuel Cell system [M]. Chengdu: University of Electronic Science and Technology of China

3. Rui Quan. Study on Some Key Problems of Fault Diagnosis and maintenance for Automotive Fuel CellSystem [M]. WuHan: Wuhan university of Technology, 2011-06.

4. DanLu. Research on hydrogen consumption of fuel cell vehicle based on flow measurement method [M]. Beijing: Beijing Jiaotong university, 2015-06.

5. Shen C, Hou Y.P \& Yang S.J.(2011)Software Development for Hydrogen Consumption Analysis of Fuel Cell Engine.In Proceedings of 2011 Annual Meeting of China Society of automotive engineering.BeiJing.pp.167-172 